\title{
Closing the Loop: An interactive action-research conference format for delivering updated medical information while eliciting Latina patient/family experiences and psychosocial needs post- genetic cancer risk assessment
}

\author{
Deborah J. MacDonald, PhD, RN, APNG ${ }^{1}$, Julia Deri, MS, CGC ${ }^{1}$, Charité Ricker, MS, CGC ${ }^{2}$, \\ Martin A. Perez, PhD ${ }^{3}$, Raquel Ogaz, BS ${ }^{1}$, Nancy Feldman, MD ${ }^{4}$, Lori A. Viveros, MPH, \\ CHES $^{5}$, Benjamin Paz, MD ${ }^{1}$, Jeffrey N. Weitzel, MD ${ }^{1}$, and Kathleen R. Blazer, EdD, MS, \\ CGC $^{1}$ \\ ${ }^{1}$ Division of Clinical Cancer Genetics, City of Hope Comprehensive Cancer Center, Duarte, USA \\ ${ }^{2}$ University of Southern California, Keck School of Medicine, Los Angeles, CA \\ ${ }^{3}$ Director, Perez \& Associates, A Professional Clinical Psychology Corp, Pasadena, CA \\ ${ }^{4}$ Physician, Department of Medicine, Olive View-UCLA Medical Center, UCLA Jonsson \\ Comprehensive Cancer Center \\ ${ }^{5}$ Program Manager, Avon Cares for Life, Olive View-UCLA Medical Center, UCLA Jonsson \\ Comprehensive Cancer Center
}

\begin{abstract}
Objective-A patient/family-centered conference was conducted at an underserved community hospital to address Latinas' post-genetic cancer risk assessment (GCRA) medical information and psychosocial support needs, and determine the utility of the action research format.

Methods-Latinas seen for GCRA were recruited to a half-day conference conducted in Spanish. Content was partly determined from follow-up survey feedback. Written surveys, interactive discussions, and Audience Response System (ARS) queries facilitated the participant-healthcare professional action research process. Analyses included descriptive statistics and thematic analysis.

Results-The 71 attendees (41 patients and 27 relatives/friends) were primarily non-U.S. born Spanish-speaking females, mean age 43 years. Among patients, $73 \%$ had a breast cancer history; $85 \%$ had $B R C A$ testing (49\% BRCA+). Nearly all (96\%) attendees completed the conference surveys and ARS queries; $\geq 48 \%$ participated in interactive discussions. Most (95\%) agreed that the format met their personal interests and expectations and provided useful information and resources. Gaps/challenges identified in the GCRA process included pre-consult anxiety, uncertainty about reason for referral and expected outcomes, and psychosocial needs post-GCRA,
\end{abstract}

Corresponding author: Deborah J. MacDonald, PhD, RN, APNG, Division of Clinical Cancer Genetics, City of Hope - an NCIdesignated Comprehensive Cancer Center, 1500 E Duarte Rd, Duarte, CA 91010, Ph: 626-256-8662, Fax: 626-930-5495, dmacdonald@coh.org.

Ethical Standards

All human studies have been approved by the appropriate ethics committee and have therefore been performed in accordance with the ethical standards laid down in the 1964 Declaration of Helsinki and its later amendments. All persons gave their informed consent prior to their inclusion in the study.

Conflicts of Interest

The authors declare that they have no conflicts of interest. 
such as absorbing and disseminating risk information to relatives and concurrently coping with a recent cancer diagnosis.

Conclusions-The combined action research and educational conference format was innovative and effective for responding to continued patient information needs and addressing an important data gap about support needs of Latina patients and family members following genetic cancer risk assessment. Findings informed GCRA process improvements and provide a basis for theorydriven cancer control research.

\section{Keywords}

Latinas; cancer; genetics; oncology; patient conference; psychosocial

\section{Introduction}

Breast cancer is the most commonly diagnosed cancer among Latinas ${ }^{\mathrm{a}}$ [1]. Although the overall incidence is lower compared to non-Latinas, Latinas are more often diagnosed at a younger age with more locally advanced disease [2]. Younger age at onset, high risk breast cancer, and a family history of breast or ovarian cancers are associated with inherited $B R C A$ gene mutations. We previously demonstrated that $B R C A$ mutations account for a significant proportion of these cancers in Latinas [3-4]. As in other healthcare services, Latinos experience disparities in access to genetic cancer risk assessment (GCRA), a standard-ofcare medical service for persons/families suggestive of increased cancer risk. Within GCRA, personal and family medical history are used along with rapidly evolving genetic technologies and/or empiric cancer risk models to direct risk-tailored strategies to prevent an initial or subsequent cancer[5-12].

The City of Hope Cancer Screening \& Prevention Program Network (CSPPN) ${ }^{s m}$ cancer genetics team previously conducted a needs assessment of predominantly uninsured Spanish-speaking Latinas in Southern California [13]. Demonstrated interest, and commitment of the referring institution to provide GCRA patients with free follow-up cancer screening and prevention cares, led to extending the Network to this indigent healthcare system [14]. A decade later, GCRA uptake remains high, with a higher than initially expected rate of $B R C A$ mutations identified [4].

We found that in our economically and educationally disadvantaged population, Latinas presenting for GCRA possess relatively high levels of social support and self-efficacy in feeling prepared for GCRA, and low levels of cancer-specific fatalism [15]. However, little is known about the extent to which underserved Latinas comprehend, retain, and process GCRA-related information. Open-ended comments in follow-up surveys identified that Latinas desire updated cancer genetics information and follow-up care, and revealed ongoing psychosocial support needs [16]. Consequently, we held a patient/family-centered conference at our primary underserved clinic to: 1) inform our Latina patients and their family members about medical advances in cancer screening and prevention, 2) further assess their GCRA-related experiences and psychosocial needs, and 3) determine the utility of the interactive action research conference format.

\footnotetext{
a'Latino' is the most common consensus term for individuals of Spanish, Mexican, Central and South American, Cuban or Puerto Rican origin and is generally considered a more ethnically/culturally based term for individuals of the aforementioned groups.
} 


\section{Methods}

\section{Design}

As successful in our prior patient conference [17], we employed a multimodal mixed methods design integrating action research principles [18-19]. Action research uses a cyclical process of iterative reflection, inquiry, and informed action [20-21] to co-generate knowledge and enable problem solving through the direct engagement of stakeholders in the research process.

\section{Procedures}

Study approval was obtained from the COH IRB. An interdisciplinary research team of Latino and non-Latino clinical cancer genetics staff, other healthcare professionals familiar with cancer genetics research, a Latina $B R C A$ positive breast cancer survivor, and a local American Cancer Society [ACS] representative convened to develop the conference goals, agenda and format. The team selected two $B R C A$ positive family patient-relative pairs for the patient-healthcare expert panel discussion, and three healthcare professionals for podium presentations, all bilingual Latino/a.

Eligible invitees were Latinos with a personal or family history of breast or ovarian cancers seen for GCRA between 2001-2009 within the COH's CSPPN in Southern California who previously enrolled in the COH IRB-approved prospective registry. The conference brochure and all other conference materials were professionally translated into Spanish. The brochure was mailed to the 167 eligible Latinos and indicated that adult family members were also welcome to attend.

The free half-day conference was held entirely in Spanish on Saturday May 9th, 2009, at Olive View Medical Center (OVMC), a Southern California community-based health services network participating in the COH CSPPN. Attendees chose the syllabus, surveys and video-recording notice in Spanish or English. Index cards and pens were distributed to allow anonymous questions and/or comments about any aspect of the GCRA process or podium presentations. The cards were collected after each presentation and selected content was addressed. An evaluation survey was distributed at the conference conclusion. Six community patient resource/support organizations provided materials in booth exhibits and representatives who were available to speak with attendees. Complimentary amenities included food and beverages, an ice cream social and raffles (grocery cards, gift baskets, etc.).

The 3 podium presentations by providers (manuscript authors) experienced in genetic counseling, surgical oncology, or clinical psychology addressed: 1) advances in risk assessment and cancer screening recommendations for high-risk patients (CR), 2) options and techniques to reduce risk for breast and ovarian cancers (BP), and 3) coping with psychological, social and cultural issues related to this risk (MP). Presentations were followed by a process of interactive discussion sessions mediated by Audience Response System (ARS; Audience Response Systems, Inc., Evansville, IN) items, index cards comments, and verbal exchange.

\section{Measures}

Data were collected using two written surveys, ARS items, index cards, and a transcript of the entire conference. Survey items and ARS questions (described below in English) were developed and revised by the multidisciplinary/multicultural clinical cancer genetics team. 
The demographic characteristics (age, gender, marital status, number of children, education level, and place of birth) and clinical information (cancer history, BRCA status, etc.) survey consisted of check-box items and one open-ended item for comments or questions. The evaluation survey consisted of 5 Likert scale items ranging from "agree" to "disagree" and 4 open-ended items requesting feedback about the conference.

The ARS questions were: 1) Before the cancer genetics consultation, did you know why you were referred, 2) Was the time between being referred and seen stressful or challenging?, 3) Was your first consultation stressful or challenging?, 4) Was the test result visit stressful or challenging?, 5) Did you share the information obtained from the consultation and/or testing?, 6) Do you understand your cancer risk?, 7) Do you understand what needs to be done for cancer screening or prevention?, and 8) Are you able to obtain the recommended exams for cancer screening and detection? Between questions, aggregate group responses were displayed on a screen and the bilingual/bicultural moderator (MP) and the patient-pair facilitated interactive discussion among attendees. Attendees were again encouraged to actively participate in an iterative dialogue.

\section{Analyses}

Descriptive statistics were used to report survey items and participants' demographic and clinical characteristics. T-tests and Chi-square statistics or Fisher's exact tests were conducted to determine any significant differences between patient and non-patient responses. These analyses were conducted using SPSS v.16.0 (SPSS Inc, Chicago, IL). Index card comments were reviewed, assigned broad topic categories, and tallied. Openended data were transcribed verbatim. Data collected in Spanish was professionally translated into English. Bilingual/bicultural research team members reviewed the audiorecording and the Spanish and English transcripts to assure fidelity. Thematic analysis was used to review and independently analyze the Spanish and English transcripts [22-23].

\section{Results \\ Sample}

Sixty-eight (96\%) of the 71 attendees, including 41 GCRA patients, completed the baseline survey. Of these, $96 \%$ completed the Spanish version. Responders' demographic characteristics, subdivided by patients $(\mathrm{n}=41$; all female) and non-patients $(\mathrm{n}=27)$, are presented in Table 1. The mean age of responders was 43 years (range, 18-71 years). Most were female (93\%), completed at least high-school (70\%), were married/cohabitating (56\%), had children (76\%), and were from Mexico (56\%) or Central/South America (34\%). Nonpatient responders were more likely to be males and to have attended college. Utilizing the $\mathrm{COH}$ registry database demographic and clinical data, there were no significant differences between invited patient attendees and non-attendees.

\section{Clinical characteristics of the patient attendees}

Patients' cancer history and BRCA status are depicted in Table 2. All patients were female, with a mean age of 40 (range, 29-48 years), $73 \%$ had a history of breast cancer, two also had ovarian cancer (7\%), and three also had another non-BRCA related cancer (10\%). Eighty-five percent had $B R C A 1$ and $B R C A 2$ gene sequencing free-of-charge through our undeserved outreach program, of which $49 \%$ were found to have a deleterious $B R C A$ mutation. 


\section{Perceptions of the GCRA experience and access to care}

On average, $93-95 \%$ of the 41 patient attendees responded to the ARS questions assessing perceptions of the GCRA experience and access to care (Table 3). Seventy percent understood why they were referred, while $30 \%$ did not, were uncertain, or did not remember. Most found the GCRA process to be stressful or challenging while awaiting their initial appointment $(\mathrm{n}=30 ; 81 \%)$ and during this visit $(\mathrm{n}=31 ; 89 \%)$ and the results disclosure visit $(\mathrm{n}=29 ; 76 \%)$. After GCRA, 95\% of the patients shared the information (test results, implications) with at least one relative, with $81 \%$ doing so immediately, and $14 \%$ later. Two patients (5\%) did not share the information, citing lack of access to pertinent family members.

Most patient and non-patient responders indicated that they understood their cancer risks $(\mathrm{n}=56 ; 80 \%)$, although $11(20 \%)$ did not or desired more information, including information about cancer screening and prevention (7\%-9\%). Nearly all responders who indicated awareness of screening recommendations reported obtaining screening (96\%), however 11 (17\%) did not know what examinations were needed.

\section{Post-GCRA-related knowledge needs}

Participants' $(n=31)$ most frequent topics of inquiry written on the index cards were related to cancer risks and risk reduction (41\%), hormonal exposure (16\%), breast reconstruction $(12 \%)$, and age to initiate genetic testing of family members $(9 \%)$.

\section{Open-ended items and interactive discussion}

Six main themes and several sub-themes emerged from the open-ended survey items and interactive discussions. Representative verbatim quotes are presented below in English to represent key points.

\section{Personal challenges associated with the GCRA process-influence of preparedness and} support: A dominant area of the interactive discussion revolved around being inadequately prepared for GCRA (not understanding the consultative process and/or necessity) and the subsequent implications for family members and the Latina community, both locally and in their country of origin. For some, fear and anxiety delayed presenting for risk assessment.

"I did not know how important this was."

"I felt a lot of panic and postponed the appointment."

For at least one other, anxiety set in when she received her positive result and was further exacerbated when the genetics team expressed surprise with the result since the prior probability that she carried a mutation was modest.

"I didn’t really feel much stress until we actually got my result. It was a big shock to everybody, my whole team, all my doctors...that's when my stress started."

Several participants discussed the need for more time to absorb the information provided and genetic test results before discussing healthcare implications. The amount and content of the information was often viewed as overwhelming.

"...many details... a lot of information...the whole thing was very stressful."

Women also described the added burden of coping with a recent breast cancer diagnosis and treatment.

"Realizing that this disease would not allow me to be myself, do my chores, work, was a great depression...the physical change I suffered depressed me." 
The importance of having a support person present at each genetics visit was echoed by several patients.

"You should tell someone in your family about your first appointment...so that this person can process the information, understand or whatever and make sure they join you at the moment you are given the results, even if they have to take turns, because it's a great help to rely on someone."

Educating self in order to inform family and community: The need for ongoing education to facilitate medical/risk information sharing with family members was evident.

"I really wish to give them [relatives] more information, learn more about these genetic issues."

"More than anything I am truly thankful for everything I have learned, everything I have been taught. What I actually really wanted to do [re learning more] was let my [relatives] know [of cancer risk]."

Sense of family and community responsibility: Patients also discussed their perceived responsibility to share information with, and motivate, others.

"I'd like to let the rest of you know that outside there are a lot of people who did not have the opportunity of attending this conference. I invite you to spread the information around, information we now have, so that we all help each other."

Transitioning to survivorship: Several patients voiced how they advocated for and motivated each other:

"The most important think to bear in mind once you leave this room is that you have to keep going forward, you mustn't let this disease overcome you."

Information was seen as key to health promotion, self-efficacy.

"With the information you can gather, you can be very positive about the fact that we can all make it when it comes to cancer."

Faith as an adaptive coping mechanism: Religious beliefs helped mobilize coping, as did being proactive.

"When I first heard the news, the first thing at the top of mind was, oh no, I'll never be in love again, I'm going to die... but then I remembered that Jesus has worked a miracle for us, and I said to myself, no, where is the Christian in me? I must start praying right now."

Need to educate the medical community: The final theme revealed was the importance of educating healthcare professionals, to reduce misguidance and enhance referral of patients for GCRA. This is illustrated by a $B R C A$-carrier participant reporting her physician's advice:

"No, you are very young...don't worry [about breast cancer risk], because you do not smoke, you don't drink..."

\section{Conference evaluation}

Nearly all attendees (99\%) completed the evaluation survey. At least $94 \%$ agreed or strongly agreed that the conference met their expectations, addressed issues of interest to them, provided information and resources that they would use in the future, and that they would attend a similar conference again. The most frequent topics suggested for future conferences pertained to psychosocial support for family members, cancer prevention and keeping current with cancer-related information. Attendees would bring family members, mostly 
spouses and close female relatives, as well as friends to a similar conference. The only suggested change in conducting the conference was to allow even more time for questions.

\section{Discussion}

To our knowledge, our study represents the first time a conference format has been used to provide Latinas with updates in cancer genetics following GCRA and the first conference to explore Latinas' post-GCRA-related experiences and needs. We held the conference in response to the request for updated genetics information and on-going psychosocial support identified in long-term follow-up data from our underserved Latina patients [16]. We opted for a conference format because limited financial and staff resources preclude additional GCRA visits and disseminating information through a newsletter or other media would not permit personal interactions, psychosocial support, or additional needs exploration. Findings demonstrated feasibility, acceptability, and effectiveness of the action-research conference format for delivering updated medical information while directly eliciting ongoing postGCRA issues/needs.

Attendees valued the information provided and were grateful for the opportunity to participate in a conference that was free, in their native language, and dedicated to their needs. Importantly, findings were immediately translatable into more responsive clinical care and are being used to expand our theory-driven research with this population.

Our prior work identified the desire for, and success of, providing cancer genetics services in this population [14]. Bilingual genetic counselors trained in culturally sensitive GCRA, a Latina clinic coordinator/patient navigator and a physician champion help prepare patients for their appointments [15]. Nevertheless, Latinas in our study discussed that the process was stressful or challenging. Several highlighted the importance of having a family member or friend present at their genetic appointments for psychosocial support as well as to assist with information comprehension and retention.

Poor understanding of, and distress associated with, the GCRA process at referral, while awaiting, and after risk level notification was also identified in free-text data from genetics patients responding to mailed questionnaires in Wales [24]. The authors suggested that means to better inform women of the process and timeline involved in GCRA may help prepare them for, and have more realistic expectations of, GCRA. The similarity to our findings is noteworthy despite ethnic and other demographic, clinical, risk level, and GCRA process delivery differences.

We identified the need to provide assistance with risk communications post-GCRA. Supporting our prior finding that Latinas and non-Latinas share similar beliefs regarding duty to inform relatives of hereditary cancer risk [25], Latinas expressed a responsibility and desire to personally share cancer risk information with relatives. Concomitant with this desire was their struggle to balance information dissemination without instilling anxiety or fear in relatives in countries with extremely limited GCRA resources. Avoiding potential harm has also hindered family cancer risk discussions in non-Latinas [26-27]. Of note, infrequent contact and geographical or emotional distance were not reported to censor risk communications. This is in contrast with our prior work and that of others in primarily nonLatina populations [28-29].

Being well-informed was valued as empowering not for one's personal healthcare but also for the sake of others. Consistent with the Latino concept of familia, in which 'family' may include non-biological others, the desire to take on the role of spokesperson extended to the community. "Spreading the word" to non-relative others appeared more ubiquitous for Latinas than in the literature or observed in our non-Latina patients. There was no evidence 
of stigma, shame, or secrecy that might impair information flow as reported in a focus group study of Latinos queried about beliefs and attitudes towards cancer and $B R C A$ testing [30]. However, only 3 of the 51 participants (57\% female) were aware of $B R C A$ testing prior to participation. Once informed, most viewed this testing favorably and thought that culturally sensitive educational efforts might lower barriers to information sharing.

Another finding was that faith in God, oneself, and genetics professionals instilled empowerment and catalyzed moving from fatalism to survivorship. This suggests that providers who cultivate positive attitudes about cancer genetics/risk reduction may improve patients' psychosocial well-being.

As we previously found in non-Latinas [31], some participants were dismayed that their physicians' did not recognize the need for a genetics referral. We expect that this will care barrier will diminish over time given the current paradigm shift to personalized genetic/ genomic medicine [9]. However, it is important to note that knowledge may not always translate into referral by practitioners in underserved settings.

Our study exemplifies one of few efforts to provide Latino/a patients with current health information while addressing and further exploring post-GCRA needs. Most studies to date investigating psychological or behavioral outcomes of genetic testing for hereditary breast and ovarian cancer (HBOC) risk have focused on non-Latina whites, such as the one-day retreat held in Vermont for persons seen at two local cancer genetics programs. The investigators provided updated medical management and addressed support needs for the 41attendees from 22 families. Comparable to our study, most attendees were female (80\%) and $50 \%$ had a prior cancer history; attendees appreciated the opportunity to discuss their experiences with others in similar circumstances and would attend a similar retreat again. In contrast to our study, the attendees were highly educated and the majority had healthcare insurance. Ethnicity was not reported, likely due to little diversity. Experiences and needs related to the GCRA process were not specifically assessed.

Our participants highly valued the opportunity to share their concerns with Latina breast cancer advocates and partake of the community resources provided. Few patient advocacy and community support resources specifically address the additional issues and needs of younger individuals and families with HBOC. Although genetics advances have catapulted the development of resources for this group by national organization such as FORCE (www.facingourrisk.org) and Bright Pink (www.bebrightpink.org), who have some Spanish resources, use by Latinas may be limited by access to and familiarity with the Internet.

FORCE has held an annual conference in Florida since 1996 to provide a forum targeted primarily to $B R C A$ carriers and their families. Sessions discuss the latest advances in HBOC risk, provide an opportunity for networking and peer support, and may be available for viewing via the FORCE website. To our knowledge, data regarding the GCRA experience and ongoing needs of conference attendees are not formally collected. Similarly, the advocacy groups Living Beyond Breast Cancer and The Young Survival Coalition (www.C4YW.org) teamed in 2010 to hold annual conferences addressing medical and psychosocial issues faced by young women with breast cancer. While these organizations provide conference scholarships for some attendees, costs and distance as well as language barriers may prevent participation for others.

Finally, the Latinas in our study expressed understanding of genetic-related cancer risk but had questions about risks after risk reduction procedures or cancer treatment; hormone use; reconstructive surgery; and the appropriate age for genetic testing in their relatives. Similar post-GCRA information and psychosocial support needs were described in a review of studies reporting ongoing concerns among women with a $B R C A$ mutation[32]. 
Given the above findings, we: 1) recently initiated a study of the impact of adapted motivational interviewing on GCRA preparedness for underserved, primarily Spanishspeaking Latinas; 2) are placing further emphasis on bringing a trusted person to all genetic appointments; and 3) have adapted the information content during genetic counseling to better address each counselee's individual needs and health status. We are also facilitating $B R C A$ testing initiatives in Mexico through physician training and research collaborations.

\section{Limitations}

Generalizability is limited by the sample size, single geographical region, potential recall bias, and one-time event. Nonetheless, findings echo many of the experiences and needs expressed by our non-Latina patients $[17,28,33]$ and other studies with high-risk nonLatina breast cancer patients [34-36]. Although attendees were demographically representative of Latinas in our clinics, they may represent a select group with on-going post-GCRA needs and may not be representative of Latinas elsewhere. Time in the U.S. and acculturation, not measured, may have influenced attendance and responses. Further, most participants are in a research program wherein a patient navigator facilitates obtaining risk management cares, thus the high rate of access to recommended post-GCRA healthcare may not be representative of other underserved Latinos

\section{Conclusions and Future Directions}

Responding to and further exploring Latinas' post-GCRA information and psychosocial support needs using multimodal action research in a patient/family-centered conference was innovative, effective, and addresses a key disparity in cancer control research. Findings revealed post-GCRA needs similar to non-Latinas and allowed immediate translation to modify our risk assessment process. Findings also suggest support for Leventhal's Illness Representation Model [37-41], which will be used to guide future research to enhance evidence-based care for ethnically diverse families at high risk for cancer. Funding for similar conferences will be sought.

\section{Acknowledgments}

Funding for the conference was provided by the Regents of the University of California Breast Cancer Research Program, Grant Number 14MG-0189, and the Los Angeles County affiliate of Susan G. Komen for the Cure and in part by a General Clinical Research Center grant from NIH (M01RR000043). The conference was sponsored by Avon Cares for Life, Olive View-UCLA Medical Center.

The authors are grateful to the patient panel members and participants for openly sharing their experiences and insights, and the community exhibitors for their time and materials. We also thank the planning committee including Angela Garrido, RN, NP, and OVMC cancer genetics clinic coordinator Evelyn Escobedo; genetic counselors Kimberly Banks, Cheryl Cina, Aura Janze, and Jocelyn Chappell, RN, MSN; Chrissy Kim of the ACS; Katherine McKenzie, PhD of the CBCRP; Noemi Maldonado; conference coordinator Gloria Nuñez; Sharon Sand, Jerry Ruiz (in memoriam) and other COH and OVMC staff who provided logistical support, and Aparna Desai, Shawntel Payton, and Tracy Sulkin for assistance with manuscript preparation.

\section{References}

1. Society, AC., editor. ACS. California Cancer Facts and Figures 2004. Oakland, California: American Cancer Society, California Division and Public Health Institute, California Cancer Registry; 2004.

2. ACS. Cancer Facts \& Figures for Hispanics/Latinos 2006-2008. Atlanta, GA: American Cancer Society; 2006. p. 1-32.

3. Weitzel JN, Lagos V, Blazer KR, et al. Prevalence of BRCA mutations and founder effect in highrisk Hispanic families. Cancer Epidemiol Biomarkers Prev. 2005; 14(7):1666-1671. [PubMed: 16030099] 
4. Weitzel, J.; Clague, J.; Ogaz, R., et al. Prevalence and ancestral origin of Hispanic BRCA mutations: Insights for ancestry informed genetic cancer risk assessment. Chicago, IL: American Society of Clinical Oncology Annual Meeting; 2011.

5. American Society of Clinical Oncology (ASCO). American Society of Clinical Oncology policy statement update: Genetic testing for cancer susceptibility. J Clin Oncol. 2003; 21(12):2397-2406. [PubMed: 12692171]

6. Daly MB, Axilbund JE, Bryant E, et al. Genetic/Familial high-risk assessment: breast and ovarian. J Natl Compr Canc Netw. 2006; 4(2):156-176. [PubMed: 16451772]

7. NCCN. NCCN clinical practice guidelines in oncology V.1.2011: Genetic/familial high-risk assessment: breast and ovarian. NCCN Clinical Practice Guidelines, April 7, 2011 edn. 2011

8. MacDonald, DJ. Establishing a Cancer Genetics Service. In: Kuerer, H., editor. Kuerer's Breast Surgical Oncology. New York, NY: McGraw-Hill; 2010. p. 73-79.

9. Weitzel JN, Blazer KR, MacDonald DJ, Culver JO, Offit K. Genetics, Genomics and Cancer Risk Assessment: State of the art and future directions in the era of personalized medicine. CA Cancer J Clin. 2011; 61(5):327-359.

10. Weitzel JN, Lagos VI, Cullinane CA, et al. Limited family structure and BRCA gene mutation status in single cases of breast cancer. JAMA. 2007; 297(23):2587-2595. [PubMed: 17579227]

11. Weitzel J. Evidence for Advice: Reduction in Risk of Breast or Ovarian Cancer After SalpingoOophorectomy in Carriers of BRCA1 or BRCA2 Mutations. Breast Diseases: A Year Book Quarterly. 2004; 14(4):354-356.

12. Weitzel JN. Genetic cancer risk assessment: Putting it all together. Cancer. 1999; 86(Suppl)(11): 2483-2492. [PubMed: 10630174]

13. Ricker CN, Hiyama S, Fuentes S, et al. Beliefs and interest in cancer risk in an underserved Latino cohort. Prev Med. 2007; 44(3):241-245. [PubMed: 17027932]

14. Ricker C, Lagos V, Feldman N, et al. If we build it...will they come? - Establishing a cancer genetics services clinic for an underserved predominantly Latina cohort. J Genet Couns. 2006; 15(6):505-514. [PubMed: 17106633]

15. Lagos VI, Perez MA, Ricker CN, et al. Social cognitive aspects of underserved Latinas preparing to undergo genetic risk assessment for hereditary breast and ovarian cancer. Psycho-Oncol. 2008; 17(8):774-782.

16. Habrat, D.; MacDonald, DJ.; Lagos, V.; Weitzel, JN. Assessing Patients' Perceptions of Genetic Cancer Risk Assessment and Post Counseling Needs. Duarte, CA: City of Hope Eugene and Ruth Roberts Summer Student Academy; 2008.

17. Huizenga, CR.; MacDonald, DJ.; Sand, SR., et al. Closing the Loop and Opening Vistas: A Conference to Explore the Genetic Counseling Needs and Experiences of BRCA Carriers and Their Families; American Society of Human Genetics; Honolulu, Hawaii: 2009 Oct. p. 335

18. Meyer J. Using qualitative methods in health related action research. Br Med J. 2000; 320(7228): 178-181. [PubMed: 10634744]

19. Morrison B, Lilford R. How can action research apply to health services? Qual Health Res. 2001; 11(4):436-449. [PubMed: 11521603]

20. Sagor, R. Guiding School Improvement with Action Research. Alexandria, VA: Association for Supervision and Curriculum Development; 2000.

21. Frost, P. Principles of the action research cycle. In: Ritchie, R.; Pollard, A.; Frost, P., editors. Action Research: a Guide for Teachers - Burning Issues in Primary Education. Birmingham, England: National Primary Trust; 2002. p. 24-32.

22. Denzin, NK.; Lincoln, YS. Strategies of qualitative inquiry. 2nd ed. Thousand Oaks, CA: Sage; 2003.

23. Braun V, Clarke V. Using thematic analysis in psychology. Qualitative Reseach in Psychology. 2006; 3(2):77-101.

24. Phelps C, Wood F, Bennett P, Brain K, Gray J. Knowledge and expectations of women undergoing cancer genetic risk assessment: a qualitative analysis of free-text questionnaire comments. J Genet Couns. 2007; 16(4):505-514. [PubMed: 17318449] 
25. MacDonald DJ, Sarna L, Giger JN, Bastani R, van Servellen G, Weitzel JN. Comparison of Latina and non-Latina White women's beliefs about communicating genetic cancer risk to relatives. J Health Commun. 2008; 13(5):465-479. [PubMed: 18661388]

26. Segal J, Esplen MJ, Toner B, Baedorf S, Narod S, Butler K. An Invesigation of the Disclosure Process and Support Needs of BRCA1 and BRCA2 Carriers. American Journal of Med Genetics. 2004; 125A:267-272.

27. Kenen R, Arden-Jones A, Eeles R. We are talking, but are they listening? Communication patterns in families with a history of breast/ovarian cancer (HBOC). Psycho-Oncol. 2004; 13(5):335-345.

28. MacDonald DJ, Sarna L, van Servellen G, Bastani R, Giger JN, Weitzel JN. Selection of family members for communication of cancer risk and barriers to this communication before and after genetic cancer risk assessment. Genet Med. 2007; 9(5):275-282. [PubMed: 17505204]

29. Mellon S, Berry-Bobovski L, Gold R, Levin N, Tainsky MA. Communication and decisionmaking about seeking inherited cancer risk information: findings from female survivor-relative focus groups. Psycho-Oncol. 2006; 15(3):193-208.

30. Kinney AY, Gammon A, Coxworth J, Simonsen SE, Arce-Laretta M. Exploring attitudes, beliefs, and communication preferences of Latino community members regarding BRCA1/2 mutation testing and preventive strategies. Genet Med. 2010; 12(2):105-115. [PubMed: 20061960]

31. MacDonald, DJ. Women's perceptions of the personal and family impact of genetic cancer risk assessment: Focus group findings; University of Arizona College of Nursing 50th Anniversary Research Conference; Tucson, AZ:

32. Crotser CB, Boehmke M. Survivorship considerations in adults with hereditary breast and ovarian cancer syndrome: state of the science. J Cancer Surviv. 2009; 3(1):21-42. [PubMed: 19165605]

33. Culver JO, MacDonald DJ, Thornton AA, et al. Development and evaluation of a decision aid for BRCA carriers with breast cancer. J Genet Couns. 2011; 20(3):294-307. [PubMed: 21369831]

34. Kenen RH, Shapiro PJ, Friedman S, Coyne JC. Peer-support in coping with medical uncertainty: discussion of oophorectomy and hormone replacement therapy on a web-based message board. Psycho-Oncol. 2007; 16(8):763-771.

35. Werner-Lin A. Formal and informal support needs of young women with BRCA mutations. J Psychosoc Oncol. 2008; 26(4):111-133. [PubMed: 19042275]

36. Hughes L, Phelps C. "The bigger the network the bigger the bowl of cherries...": exploring the acceptability of, and preferences for, an ongoing support network for known BRCA 1 and BRCA 2 mutation carriers. J Genet Couns. 2010; 19(5):487-496. [PubMed: 20411314]

37. Leventhal H, Kelly K, Leventhal EA. Population risk, actual risk, perceived risk, and cancer control: a discussion. J Natl Cancer Inst Monogr. 1999; (25):81-85. [PubMed: 10854461]

38. Kelly K, Leventhal H, Marvin M, et al. Subjective and objective risk of breast cancer in Ashkenazi Jewish individuals at risk for BRCA1/2 mutations. Genet Test. 2004; 8(2):139-147. [PubMed: 15345111]

39. Kelly K, Leventhal H, Andrykowski M, et al. Using the common sense model to understand perceived cancer risk in individuals testing for BRCA1/2 mutations. Psycho-Oncol. 2005; 14(1): 34-48.

40. Hamilton AS, Hofer TP, Hawley ST, et al. Latinas and Breast Cancer Outcomes: Population-Based Sampling, Ethnic Identity, and Acculturation Assessment. Cancer Epidem Biomar. 2009; 18(7): 2022-2029.

41. Costanzo ES, Lutgendorf SK, Roeder SL. Common-sense beliefs about cancer and health practices among women completing treatment for breast cancer. Psycho-Oncol. 2011; 20(1):53-61. 
Table 1

Sample Demographic and Clinical Characteristics

\begin{tabular}{|c|c|c|c|c|}
\hline & $\begin{array}{l}\text { Total } \\
\text { n }(\%)\end{array}$ & $\begin{array}{c}\text { Patients } \\
\text { n }(\%)\end{array}$ & $\begin{array}{l}\text { "Non- } \\
\text { patients"** } \\
\text { n (\%) }\end{array}$ & $\begin{array}{c}P \\
\text { value }\end{array}$ \\
\hline & 68 (95.6) & $41(60.3)$ & $27(39.7)$ & \\
\hline Age & & & & .379 \\
\hline Mean & 43 & 44 & 42 & \\
\hline Range & $18-71$ & $27-65$ & $18-71$ & \\
\hline Gender & & & & .004 \\
\hline Female & $63(92.6)$ & $41(100)$ & $22(81.5)$ & \\
\hline Male & $5(7.4)$ & $0(0)$ & $5(18.5)$ & \\
\hline Marital status & & & & .509 \\
\hline Married/living together & $38(55.9)$ & $24(58.5)$ & $14(51.9)$ & \\
\hline Not married $l$ & $29(42.6)$ & $16(33)$ & $13(48.1)$ & \\
\hline Children & & & & .360 \\
\hline Yes & $52(76.5)$ & $33(80.5)$ & $19(70.4)$ & \\
\hline No & $14(20.5)$ & $7(17.1)$ & $7(25.9)$ & \\
\hline Education Level & & & & .020 \\
\hline Elementary & $20(29.4)$ & $13(31.7)$ & $7(25.9)$ & \\
\hline High school & $19(27.9)$ & $14(34.1)$ & $5(18.5)$ & \\
\hline Some college & $22(32.4)$ & $10(24.4)$ & $12(44.4)$ & \\
\hline College graduate & $7(10.3)$ & $4(9.8)$ & $3(11.1)$ & \\
\hline Country of Birth & & & & .840 \\
\hline Mexico & $38(55.9)$ & $24(58.5)$ & $14(51.9)$ & \\
\hline United States & $6(8.8)$ & $4(9.6)$ & $2(4.9)$ & \\
\hline Other $^{2}$ & $23(33.8)$ & $13(31.7)$ & $10(37.0)$ & \\
\hline Preferred Language $^{+}$ & & & & .654 \\
\hline Spanish & $65(95.6)$ & $39(95.1)$ & $26(96.3)$ & \\
\hline English & $3(4.4)$ & $2(4.9)$ & $1(3.7)$ & \\
\hline Cancer History & & & & .000 \\
\hline Yes & 30 & 30 & 0 & \\
\hline No & 38 & 11 & 27 & \\
\hline \multicolumn{5}{|l|}{ Genetic Status } \\
\hline$B R C A$-mutation positive & & $20(29.4)$ & & \\
\hline$B R C A$-mutation negative & & $14(20.6)$ & & \\
\hline$B R C A$-VUS ${ }^{3}$ & & $1(1.8)$ & & \\
\hline
\end{tabular}

Fam Cancer. Author manuscript; available in PMC 2013 September 01. 


\begin{tabular}{lcccc}
\hline & $\begin{array}{c}\text { Total" } \\
\text { n(\%) }\end{array}$ & $\begin{array}{c}\text { Patients } \\
\mathbf{n}(\%)\end{array}$ & $\begin{array}{c}\text { "Non- } \\
\text { patients"*** } \\
\text { n (\%) }\end{array}$ & $\begin{array}{c}\boldsymbol{P} \\
\text { value }\end{array}$ \\
\hline No $B R C A$ testing & $6(8.8)$ \\
\hline
\end{tabular}

Percent totals may not equal $100 \%$ due to missing data.

Based on 68/71(96\%) attendee voluntary survey completion.

** Non-patients = family members/friends of patients.

${ }^{+}$Based on choice of survey completed

1 Single, divorced, widowed.

2 Columbia, El Salvador, Guatemala, Honduras, Peru, Venezuela.

$3^{3}$ VUS $=$ variant of uncertain significance. 


\section{Table 2}

Patient Clinical Characteristics $(n=41)$

\begin{tabular}{lcc}
\hline Characteristics & n & \% \\
\hline Cancer History & 11 & 26.8 \\
No & 30 & 73.2 \\
Yes & 25 & 83.3 \\
$\quad$ Breast only & 2 & 6.7 \\
Breast and ovarian & 3 & 10.0 \\
Breast and other ${ }^{1}$ & & \\
\hline Age at Breast Cancer Diagnosis & & \\
Range & $29-48$ & -- \\
Mean & 40 & -- \\
\hline
\end{tabular}

\section{GCRA Status}

Genetic counseling and testing $\quad 35 \quad 85.4$

$\begin{array}{lll}\text { Genetic counseling only } & 6 & 14.6\end{array}$

\section{BRCA Status}

\begin{tabular}{lcc} 
Positive & 20 & 48.8 \\
Negative & 14 & 34.1 \\
VUS $^{2}$ & 1 & 2.4 \\
\hline
\end{tabular}

1 Other reported cancers include thyroid, skin and stomach

2 VUS = variant of uncertain significance 
Table 3

Latina Conference Attendee ARS Responses

\begin{tabular}{|c|c|c|}
\hline \multicolumn{3}{|c|}{$\begin{array}{l}\text { Q1. Did you know why you were referred for GCRA? } \\
\text { n=61 }\end{array}$} \\
\hline & $\mathbf{n}$ & $\%$ \\
\hline No GCRA & 15 & 24.5 \\
\hline Received GCRA & 46 & 75.4 \\
\hline Yes & 32 & 69.6 \\
\hline No & 7 & 15.2 \\
\hline Had some idea, but confused & 6 & 13.0 \\
\hline Do not remember & 1 & 2.2 \\
\hline
\end{tabular}

Q2. Was the time between referral and your GCRA appointment stressful or challenging? $\mathbf{n}=\mathbf{5 5}$

\begin{tabular}{|l|c|c|}
\hline & $\mathbf{n}$ & \% \\
\hline No GCRA & 18 & 32.7 \\
\hline Received GCRA & 37 & 67.3 \\
\hline Yes & 30 & 81.1 \\
\hline No & 5 & 13.5 \\
\hline Do not remember & 2 & 5.4 \\
\hline
\end{tabular}

Q3. Was your first GCRA consultation stressful or challenging? $\mathbf{n}=\mathbf{5 9}$

\begin{tabular}{|l|c|c|}
\hline & $\mathbf{n}$ & $\boldsymbol{\%}$ \\
\hline No GCRA & 24 & 40.7 \\
\hline Received GCRA & 35 & 59.3 \\
\hline Yes & 31 & 88.6 \\
\hline No & 3 & 8.6 \\
\hline Do not remember & 1 & 2.8 \\
\hline
\end{tabular}

Q4. Was the second visit for test results stressful or challenging? $\mathbf{n}=59$

\begin{tabular}{|l|c|c|}
\hline & $\mathbf{n}$ & $\boldsymbol{\%}$ \\
\hline No GCRA & 21 & 35.6 \\
\hline Received GCRA & 38 & 64.4 \\
\hline Yes & 29 & 76.3 \\
\hline No & 8 & 21.1 \\
\hline Do not remember & 1 & 2.6 \\
\hline
\end{tabular}

Q5. Did you share the information that you obtained from the GCRA consultation and/or testing? $\mathrm{n}=62$

\begin{tabular}{|l|c|c|}
\hline & $\mathbf{n}$ & \% \\
\hline No GCRA/testing & 19 & 30.6 \\
\hline Received GCRA/testing & 43 & 69.4 \\
\hline
\end{tabular}




\begin{tabular}{|c|c|c|}
\hline \multicolumn{3}{|c|}{$\begin{array}{l}\text { Q5. Did you share the information that you obtained from the GCRA consultation and/or testing? } \\
\text { n=62 }\end{array}$} \\
\hline & $\mathbf{n}$ & $\%$ \\
\hline Yes: shared immediately & 35 & 81.4 \\
\hline Yes: took time to share & 6 & 13.9 \\
\hline No: thought it was irrelevant & 0 & 0 \\
\hline No: no access to pertinent relatives & 2 & 4.7 \\
\hline
\end{tabular}

\begin{tabular}{|l|c|c|}
\hline $\begin{array}{l}\text { Q6. Do you understand your risk? } \\
\text { n=64 }\end{array}$ & $\mathbf{n}$ & $\%$ \\
\hline & 8 & 12.5 \\
\hline No GCRA & 56 & 87.5 \\
\hline Received GCRA & 45 & 80.3 \\
\hline Yes & 1 & 1.8 \\
\hline No & 10 & 17.9 \\
\hline Have an idea, but need more info & \multicolumn{2}{|l}{} \\
\hline
\end{tabular}

\begin{tabular}{|c|c|c|}
\hline \multicolumn{3}{|c|}{$\begin{array}{l}\text { Q7. Do you understand what needs to be done for cancer screening and prevention? } \\
\mathrm{n}=66\end{array}$} \\
\hline & $\mathbf{n}$ & $\%$ \\
\hline No GCRA & 7 & 10.6 \\
\hline Received GCRA & 59 & 89.4 \\
\hline Yes & 49 & 83.0 \\
\hline No & 1 & 1.7 \\
\hline Need more info re: br ca & 5 & 8.5 \\
\hline Need more info re: ov ca & 4 & 6.8 \\
\hline
\end{tabular}

\begin{tabular}{|c|c|c|}
\hline \multicolumn{3}{|c|}{$\begin{array}{l}\text { Q8. Are you able to obtain the recommended exams for cancer screening and detection? } \\
\mathrm{n}=66 \text { ? }\end{array}$} \\
\hline & $\mathbf{n}$ & $\%$ \\
\hline Yes & 52 & 78.8 \\
\hline No & 3 & 4.5 \\
\hline Do not know of needed exams & 11 & 16.7 \\
\hline
\end{tabular}

"No GCRA" was not an option 